\title{
From the perspective of commercial law and public administration
}

\section{theory of Chinese traders}

\author{
Yu Meiling ${ }^{1}$ \\ ${ }^{1}$ School of Humanities and Social Science, North China Electric Power University, Beijing, 102206
}

Keywords: traders, the principal position of commercial law and public administration

\begin{abstract}
The author from the reasons of the existence of traders, and the pros and cons of traders exist, traders in the dominant position of commercial law and governance problems of mobile vendors in China and foreign for organising and tranter management reference and discuss.
\end{abstract}

\section{Introduction}

Tranter refers to the urban vulnerable groups, providing the service or profit by selling goods to make a living in the streets. The author in the process of studies and commercial law, the traders to speculate in the position in business subject.At the same time, tranter caused by urban public management problem has caused the wide attention of the society.First, tranter compared with fixed business outlets and obtain business license of individual industrial and commercial households in the field of commercial law should be decided by the particularity of qualitative is a problem of current vendor.Second, the existence of the traders, both the rationality of the existence and social development within the positive, and the external negative.For its dual attribute, in the social and public management should be how to avoid negative, exert its positive become a difficult problem.Finally, the "chengguan" mentioned in recent years, people think of is the violence law enforcement of the floating peddlers. The conflict between administrative law enforcement of urban management and tranter, how should solve, involved in our country should be from the "type" to "service-oriented government" social management problems, including the way of law enforcement of administrative law enforcement organs and the law enforcement purposes.

\section{Analysis The Reason Of Traders}

With the speeding up of urbanization, a large number of migrant workers into the city;As the university enrollment expansion, a large number of laid-off workers.In the flow of migrant workers and laid-off workers as the main vendors are widespread in the city.however, the rites, to officer, department of city "in the evening, evening sometimes, and common vendor woman". Thus it can be seen as early as the western zhou dynasty, tranter has become an indispensable part of people's life.Ancient people initially may only be put production of crops to exchange with others on their necessities.Unskilled people, however, is to produce crops, food for a long time to get the market to sell, this business model became they are a means of making a living.Therefore, tranter business model from ancient continues today, with the rationality of its existence.

Tranter stalls along the street, selling, most vendors management tool is just a tricycle, a wheelbarrow, a square table, a pedal-driven vehicles and so on.Its simple tools, don't have to deal with the business license, do not need to store rent, without having to pay taxes, determines the 
operating costs of the mobile vendors with low relative to the individual and industrial and commercial door, open flow operation easy, easy.Therefore, traders profit greatly ascend.Seeking to maximize the interests of the driver is the direct cause of traders.

The alleys tranter, meet the demand of the people's life greatly.The social and economic development, people's market demand is growing. The diversity of the materialneeds of the masses of growing, the characteristics of comprehensiveness.Usually, the urban planning is not able to fully satisfy people's demand for urban functions.And mobile vendors peddle, make people can buy the material life need at any time, meet their demand for external.In a nutshell, tranter on make up for the defect of city function plays an irreplaceable role.

According to statistics, tranter half are migrant workers in the crowd.Due to the accelerating urbanization process, a large number of rural surplus labor into cities, but city are not that many jobs for the migrant workers.For them, because of the low degree of its culture, also have no skill.And low cost, less investment, quick effect, simple and convenient operation of unincorporated business model has become the good choice of the breadwinner.

Population continues to grow, university enrollment expansion, resulting in low employment rate, the unemployment rate to the social situation.As traders, only need to spend a few price could buy management tools, low-cost business model, has become the unemployed a best choice.Was forced by life, of course, the people have the right to find a way to not damage the interests of others to make a living, make oneself to be able to live on the margins of society.

According to statistics, most of the mobile vendors are low income, life not guaranteed economic source group. Realized that along the street for a living, selling to earn living expenses.

\section{The Pros and Cons of Traders Exist}

Tranter convenient people's life.On the one hand, because many middle-income workers spending power is low, meal time is tight.The street vendors selling commodity prices were low, less time, at this point the street food vendors became their best choice.Fixed stores, on the other hand, usually can not meet the residents increasing material demand, traders make up for the lack of commercial function.

Traders to promote employment, and promote social stability.The unemployment rate increase, increases social unstable factors.Due to tranter small investment, low risk, low cost, quick effect, the characteristics of the management mode of hawkers can solve the problem of employment, many old, no skills, laid-off unemployment, to maintain life.Unemployment rate, the society will be more stable.

The traders to promote the Chinese traditional culture heritage.Someone once said: "the city is like an open book, from which can read people's cultural qualities and ambitions.", "some lousy economic form, is colorful Mosaic economy."Traders from the western zhou dynasty existing in our country, in the process of flow peddler continues down, must have the Chinese traditional culture heritage.Flow vendors usually making craft of snacks, clay, some street food, toys, such as painting long carried on the inheritance of Chinese traditional art.

\section{On the Other Hand, The Existence of the Traders Have External Negative}

The quality of the traders, the consumer rights and interests are not guarantee.Mobile traders, the biggest characteristic is its liquidity is therefore often appear street vendors selling goods do not conform to the requirements of the quality, health, and then in place continue to sell, make the purchase after consumers find street vendors selling substandard goods. The rights and interests of 
consumers are highly.[1]

Traders of city appearance and environmental sanitation, traffic, market order.First of all, as is often the case, after food vendors stalls, will trash left in the streets, affects the city appearance and environmental sanitation city.Secondly, the road itself is for cars, mobile vendors crowding the streets, make a person more congested, car social order disorder.Finally, similar to the flow of the barbecue vendors often in the residential area near the business into the middle of the night, seriously affect the residents' life.

\section{Traders in Our Country the Status of Commercial Law}

Nowadays, tranter abound, has become a main management mode of our country's market.But traders in our country has not been included in the scope of the business main body in the awkward position.Business main body is to point to in accordance with the law to participate in commercial legal relationship, will be able to conduct commercial act in its own name, to enjoy the rights and obligations.Enterprises, individual businesses and rural contractor is the legal main body of the dealer.Business main body must conform to the four constitutive requirements: (1) the contractor must be the main body is in commercial behavior, and the merchant shall have specificity;(2) suppliers by subject must oneself is the behavior of the main body, is the master of the specific commercial business activities, is the rights and obligations of the actual business behavior to bear;(3) business main body must be constantly engaged in the identity of profit-making behavior, by chance in a profitable activities of individuals or organizations usually do not belong to the merchant;(4) business main body should take for his professional specific profit-making activities or regular business, engaged in the commercial profit activists in accordance with the law of many countries also does not belong to the merchant.The author thinks that traders have difference in individual businesses, enterprises and leaseholding farm households, such as the main body, the essential characteristics of the existence of fair and reasonable.Have some drawbacks, but also its advantages.With the development of social economy, legislators should face up to tranter, be included in the main body, be juxtaposed with enterprises, individual businesses and leaseholding farm households, the main body, and according to its unique properties, to supervise and control the traders. When it comes to management methods, the author thinks that the management style of six to one, can effectively protect tranter management order, maintain social stability.First, transform government functions, from the "type" to "service-oriented government".Second, urban management play a vendor management behavior, supervise, coordinate flow with tranter illegal behavior, promptly corrected.Third, community to manage the environmental problems caused by the flow traders.Fourth, the industry association to tranter product safety and quality assessment, and issue the certificate.Fifth, tranter own self-discipline is also required.Sixth, citizens for the government, urban management management of the floating vendors shall have the right to suggest, encourage people to actively participate in social management.

\section{Problem of in the Mobile Vendors Governance in Our Country}

Cat and mouse game.Due to the operator is usually a low income flow vendors, business stalls become the only source of its economy.Therefore, urban management regulation traders like a game of cat and mouse, chengguan, tranter ran, ran to another location, continue to stall selling.It may be said: "wildfires burn born again when the spring breeze blows.", so this case law enforcement efficiency is not high, can't be effectively prohibited traders.[2]

The violence law enforcement caused the public's anger.Because of the urban management to 
play the game of cat and mouse, and decided to clamp down on street vendors' business, confiscate its management tools. This approach does have certain validity.But the negative effects of greatly, on the one hand, mobile vendors have to make a living nature, its operating tools once confiscated means selling staff lost the source of life.This is in the destruction of a person's right to exist, does not comply with the doctrine of human rights, is not conducive to social stability.Urban management flow relative to the vendor, on the other hand, is a strong group, urban management using the position of strength, the use of violence to supervise and control the flow vendors.Go against the government set up the authority figure, in sympathy with the vulnerable groups, easy to anger, undermine social stability.

The social value of trade-offs.Forbidden in our country current vendors only because current vendors strong-arming, disrupting traffic order, destruction of urban environment and health, but to ban mobile vendors will make a large number of rural migrant workers, laid-off workers and the weakness of the social low income group lose the guarantee of life source.Governments in both weigh the pros and cons, obviously the people's livelihood problem is more important for the government. The author thinks that no government, make the urban environment and makes life difficult for residents in that cannot maintain the embarrassed situation, because it is a last lifeline "vulnerable groups".Therefore, the government should not only is only management, but more should be to serve the people and society, to understand the needs of the people, set up the system guarantee the demand of the people.

\section{The Effective Draw Lessons from Foreign Traders Governance Mode}

The flow of the south Korean vendors have developed from the past single from the snack bar for a variety of clothing stores, florists, sushi and so on, formed the road culture of attracting tourists.Vendors generally don't have to pay taxes in South Korea, flows, only need to add "stall owners association" has been approved, could stall.The government strictly divided stall time and area, both is advantageous to the urban management enforcement, but also to mobile vendors consciously abide by.

In accordance with the management and convenient service (France). Flow in France, the vendor must provide the business license in accordance with the law, but also by the relevant laws, the French for foreign into chaos without any id market. Also relatively strict, usually is to take away people but not confiscation.In France, however, the flow of business licenses of the vendor to handle is very convenient, conform to the legal condition of operator can apply them in a variety of ways, can also apply for subsidy, loans and tax reduction or exemption.As long as meet the requirements of laws and regulations, the owners never leave home can get business licenses right.

Humanized management (Thailand). The streets of Bangkok flow vendors seem to follow one's inclinations, no one to manage.Actually there are special department responsible for traders, registration management.In accordance with the provisions, only in a designated blocks the restaurent.The Thai government management of the floating vendors philosophy is: the right to life is more important than the city of the vulnerable group, and also is more important than the convenience of citizens to walk.Also has the flow of illegal vendors will be punished, but the amount of the penalty are smaller, and generally will not confiscate management tool.The Thai government for mobile vendors still have to persuade: please set aside for the public traffic road of 10 meters. At the same time, the Thai government also plans to address the flow of traders, the problem of employment part make tranter automatically exit.[3]

\section{References:}


[1]ZHANG Yanji, ZHANG Lei, WU Lingyan 《The Spatial Structure of Mobile Vendor Based on Agglomeration Economies: A Case Study in Chaoyang District Beijing》,2014

[2]Wang Yaxin 《Floating Vendors Management in the City under the Theories of Public Option》,2012

[3]YUAN Zheng、XIN Kai-xuan《Management Experience of Street Vendors inOverseasCities and Inspiration》,2011 